\title{
Polypharmacy-a patient safety in older adults
}

\section{Carte $\mathrm{N}^{*}$}

Department of Nursing \& Health Professions, Manchester, NH

As the population of individuals age 65 or older continue to grow worldwide, the concern for what is known as polypharmacy continues to rise. In general, polypharmacy means taking more medication than clinically necessary and includes both prescription and overthe-counter medications [1]. Is this definition of polypharmacy adequate to support our growing older adult population? Should we as healthcare providers and advocates for quality care delivery seek a review of our older adults' medication regimens? This short review will attempt to answer these questions by examining some of the current literature on polypharmacy, the prevalence and types of unnecessary medications still being taken by the older adults and offer some possible recommendations for this continued issue in healthcare.

\section{Polypharmacy: A brief historical perspective}

About some seventy-plus years ago, the healthcare industry saw its first influx of several classes of new medications including antipsychotics, antidepressants, tranquilizers, and mood stabilizers to add to the growing antibiotic list. In fact, one of the main methods of treating individuals with psychiatric disorders was this multiple medication approach that begin in the 1950's. Today, advances in second generation medications has decreased the prevalence of multiple medications in this patient population [2]. However, treating other co-morbidities through the use of polypharmacological means is now considered part of a distinct plan of care for many patients with two or more pathological issues [2]. In fact, sometimes a new medication is added to the plan to combat the adverse effects of a current medications taken by a patient [2]. Other times, additional medications are added to the treatment regimen to increase the efficiency of the original medication [2]. Are either of these options ideal and part of best practice in today's complex healthcare environment in which there is so much more than just medications to add to the plan of care?

Other reasons for the increase use of polypharmacy in older adults is the treatment of such acute issues as the common cold, influenza, and other often self-limiting viral illnesses with antibiotics or other unnecessary prescriptions for expected symptoms of these brief and self-limiting illnesses. Should we ignore the potential complications (e.g., pneumonia and dehydration) that can arise in our older adults from these illnesses? Not in the least, but as advances in healthcare continues into the 21st Century, we need to take a different view and value of pharmacy in treating these common episodic concerns [1].

\section{Consequences of polypharmacy}

Paris [3] uses the phrase shotgun method in referencing healthcare provider who simply manage an individual's symptom separately and treating each symptom rather looking at the entire disease process. This is one negative consequence of polypharmacy. Other negative consequences include: an undue burden polypharmacy places on the healthcare system in relation to increase cost, a further increase in risk for adverse drug events (ADEs), drug-to-druginteractions, increased likely of medication non-adherence, and a reduction in functional capacity $[1,2]$. In fact, one of the highest concentration of polypharmacy use is in our older adults and the elder populations are those individuals who reside in nursing homes. At some estimates, 50\% of these individuals are taking at least one or more medications that are not medically necessary [1].

\section{Goals and expectations}

As healthcare providers, we need to advocate for change in how medications are prescribed and for what reasons. Older adults sometimes can't speak up. So, we need to speak up and stand up for patient safety and quality of care. Consider creating an open-dialogue with the older adult patient that is client-centered by reviewing each medication during a visit, including both overthe- counter and prescription medications. Many patients forget to include the medications purchases at the local pharmacy over-the-counter and these should be considered as part of the medication reconciliation [4]. Consider exploring other options beyond pharmacological measures in treating an individual's concerns such as alternative or complementary medications.

\section{Conclusion}

As healthcare providers, we must take the lead in addressing too many and unnecessary medications being prescribed to our older adults. Change begins with us as practitioners through the management, treatment, and follow up of our patients. No longer can we ignore such consequences of managing a patient's acute illness with a prescription unnecessarily. The consequences and costs are too high. We can grow together as practitioners in better understanding our patients through gathering a more quality report of their medication use. Thus, improve patient safety and quality care delivery in today's healthcare environment.

${ }^{\star}$ Correspondence to: Nicholas S. Carte, PhD, A/GNP-C, APRN, Southern New Hampshire University, 33 S. Commerical Street, Manchester, NH, 03101, Tel: 910617 2516; E-mail: n.carte@snhu.edu

Received: June 08, 2018; Accepted: June 18, 2018; Published: June 21, 2018 


\section{References}

1. Maher RL, Hanlon J, Hajjar ER (2014) Clinical consequences of polypharmacy in elderly. Expert Opin Drug Saf 13: 57-65. [Crossref]

2. Möller HJ, Seemüller F, Schennach-Wolff R, Stübner S, Rüther E, et al. (2014) History, background, concepts and current use of comedication and polypharmacy in psychiatry. Int J Neuropsychopharmacol 17: 983-996. [Crossref]
3. Paris J (2010) The use and misuse of psychiatric drugs. Oxford: Wiley-Blackwell.

4. Cornu P, Steurbaut S, Leysen T, De Baere E, Ligneel C, et al. (2012) Effect of medication reconciliation at hospital admission on medication discrepancies during hospitalization and at discharge for geriatric patients. Ann Pharmacother 46: 484-494. [Crossref]

Copyright: (C2018 Carte NS. This is an open-access article distributed under the terms of the Creative Commons Attribution License, which permits unrestricted use, distribution, and reproduction in any medium, provided the original author and source are credited. 